\title{
Diferencias en la recaudación del impuesto predial en la zona fronteriza: evidencia en los municipios de Chihuahua*
}

\author{
Jorge Ibarra Salazar** \\ Lida Sotres Cervantes***
}

Basándonos en el estudio de Ibarra y Sotres (2009), en este artículo aportamos evidencia adicional que relaciona las características de la región frontera norte y el marco institucional con la recaudación del impuesto predial. Estimamos una serie de especificaciones econométricas usando una base de datos de panel para los 67 municipios de Chihuahua correspondiente a 2002-2006. Nuestra hipótesis central es que la dinámica económica y demográfica en la zona fronteriza de Chihuahua ha originado una mayor demanda de servicios e infraestructura en los municipios fronterizos de ese estado, lo que los ha motivado a diferenciar su marco institucional para obtener mayores recursos por concepto de impuesto predial en comparación con los municipios no fronterizos. Esto es posible dado que la reforma constitucional de 1999 al Artículo 115 posibilita a los municipios modificar el marco institucional fiscal para enfrentar sus propias peculiaridades.

Palabras clave: impuesto predial, instituciones fiscales, Artículo 115 constitucional, frontera norte, Chihuahua.

Fecha de recepción: 28 de abril de 2010.

Fecha de aceptación: 17 de mayo de 2013.

Differences in Property Tax Collections in the Border Area:

Evidence from the Municipalities of Chihuahua

Based on the study by Ibarra and Sotres (2009), in this article we provide additional evidence linking the characteristics of the northern border region and the institutional framework for property tax collection. We estimate a series of econometric specifications using a panel database for the 67 municipalities in Chihuahua corresponding to 20022006. Our central hypothesis is that the economic and demographic dynamics in the

* Agradecemos el auspicio de la Cátedra de Investigación del Instituto Tecnológico y de Estudios Superiores de Monterrey (ITESM): Desarrollo Económico y Social. Este artículo se presentó en el Congreso 2009 de la Association for Borderland Studies. Agradecemos los comentarios y sugerencias de Chuthatip Maneepong, Jean Parcher, Joan Anderson, Sergio Peña y dos dictaminadores anónimos.

** Profesor asociado, Instituto Tecnológico y de Estudios Superiores de Monterrey, campus Monterrey, Departamento de Economía. Correo electrónico: <jaibarra@itesm.mx>.

*** Investigadora, Instituto Tecnológico y de Estudios Superiores de Monterrey, campus Monterrey, Departamento de Economía. Correo electrónico: <lsotres@itesm.mx>.

ESTUDIOS DEMOGRÁFICOS Y URBANOS, VOL. 29, NÚM. 1 (85), 2014, 53-87 
border area of Chihuahua has increased demand for services and infrastructure in the border municipalities of the state, which has led them to differentiate their institutional framework to obtain more funds through property tax compared with non-border municipalities. This is possible since the 1999 constitutional amendment of Article 115 allows municipalities to amend the fiscal institutional framework to deal with their own peculiarities.

Key words: property tax, fiscal institutions, Article 115 of the Constitution, northern border, Chihuahua.

\section{Introducción}

Este artículo aporta evidencia adicional del impacto de las diferencias institucionales y regionales sobre la recaudación del impuesto predial en los municipios mexicanos. Ibarra y Sotres (2009), en su estudio sobre los municipios del estado de Tamaulipas, encontraron que las diferencias institucionales y la identificación de la zona frontera norte del estado ayudaban a explicar las variaciones y las diferencias intermunicipales de la recaudación del impuesto predial. El objetivo de este estudio es explorar el efecto de las diferencias institucionales sobre la recaudación de este impuesto en los municipios del estado de Chihuahua. La hipótesis principal, de la cual se desprenden otras tres hipótesis que se describen en la sección de metodología, es que la dinámica económica y demográfica que caracteriza a la zona fronteriza del estado -y su consecuente mayor demanda de servicios públicos e infraestructura- ha motivado a los municipios de esa zona a diferenciar su marco institucional para recaudar una mayor cuantía de recursos por concepto de impuesto predial y así poder responder a estos requerimientos. De esta forma, la ubicación fronteriza ayudaría a explicar las variaciones en la recaudación de dicho impuesto entre los municipios del estado, y controlando por otros factores que influyen en la recaudación de dicho impuesto, el ingreso fiscal por predial se esperaría que fuera mayor en los municipios de esa zona.

A raíz de la reforma Constitucional al Artículo 115, los municipios fueron dotados de atribuciones para proponer a la legislatura local tanto las tablas de valores unitarios para suelo y construcción, como las tasas y tarifas para el cobro del impuesto predial, entre otras facultades. Esto dio lugar a que los municipios que así lo decidieran, hicieran uso de estas atribuciones para actualizar los valores catastrales de los predios, modificar las tasas y tarifas, implementar programas para 
hacer más eficiente la recaudación, o crear institutos municipales de catastro. Ejemplos de esto último son el Sistema Integral de Administración Catastral en el Municipio de Tampico (en Tamaulipas) y el Sistema de Gestión Catastral del Municipio de Mérida (en Yucatán), que fueron creados para aumentar la recaudación del impuesto predial. Algunos otros municipios han modificado las tasas, las tarifas y los descuentos asociados a su cobro, o han actualizado los valores unitarios del suelo y la construcción que sirven de base para el cálculo del valor catastral de los predios.

En el caso específico del estado de Chihuahua, aunque las tasas y tarifas para calcular el impuesto predial son iguales para todos los municipios (Artículo 149 del Código Municipal para el Estado de Chihuahua), las autoridades municipales en materia de catastro tienen a su alcance otras herramientas para incrementar su recaudación. Por ejemplo, cada año pueden formular y actualizar las tablas de valores unitarios para el suelo y la construcción, y remitirlas para su aprobación en la legislatura local (fracción IV del Artículo 6 de la Ley de Catastro del Estado de Chihuahua).

Otra herramienta que pueden emplear los municipios para incidir positivamente en sus finanzas es la creación de instituciones fiscales, como lo hizo el municipio fronterizo de Juárez, uno de los más importantes del estado de Chihuahua, que creó en 1995 el Instituto Municipal de Investigación y Planeación (IMIP), organismo público descentralizado del gobierno municipal cuyos objetivos son: establecer continuidad en los procesos de planeación, auxiliar a la autoridad municipal en materia de desarrollo urbano, generar estudios y proyectos urbanos, crear un banco municipal de información estadística básica, llevar a cabo la actualización cartográfica, y administrar el sistema de información geográfica municipal, entre otras acciones. Estas funciones pueden ayudar a la Dirección de Catastro del Municipio de Juárez con la información estadística y cartográfica, así como con fotos aéreas que le permiten actualizar los valores catastrales de los predios. ${ }^{1}$

Otro cambio en el marco fiscal de los municipios de Chihuahua fue la creación del Programa Integral de Modernización Catastral (Pimcat) hacia finales de 2004. Uno de los objetivos de este programa es sistematizar, agilizar y hacer eficientes los procesos de la administración catastral, así como impulsar el fortalecimiento de las finanzas públicas. ${ }^{2}$

${ }^{1}$ Para mayor detalle véase $<$ http://www.imip.org.mx $>$.

${ }^{2}$ Para mayor detalle véase $<$ http://municipios.chihuahua.gob.mx/pimcat $>$. 
Los resultados de este estudio tienen especial interés desde el punto de vista político, ya que presentan evidencias de las implicaciones de las modificaciones al Artículo 115 constitucional. ${ }^{3}$ En particular, es interesante notar que a pesar de pertenecer a un mismo estado, los municipios mexicanos pueden diseñar un marco institucional diferente en materia fiscal. Específicamente, con respecto al impuesto predial cada uno de los municipios del mismo estado puede proponer a su congreso local sus propias tablas de valores y tasas impositivas diferentes, puede realizar ajustes y cambios organizacionales y puede también implementar programas dirigidos a aumentar el monto que se recauda por concepto de impuesto predial. Tales diferencias en el marco institucional pueden explicar las variaciones en la recaudación de dicho impuesto entre los municipios de un mismo estado. Guerrero y Guillén (2000) reconocían que uno de los principales retos de la reforma constitucional referida era precisamente el cambio institucional que implicaba para el ámbito municipal de gobierno.

En la perspectiva de política fiscal, los resultados de este estudio demuestran que las diferencias en las instituciones fiscales intramunicipales, que han sido posibles por la reforma constitucional del Artículo 115, son importantes para entender las diferencias en la recaudación de predial. Con la atribución de los municipios en materia fiscal se puede aumentar la recaudación de impuestos locales; es importante considerarlo en las decisiones descentralizadoras del ingreso fiscal. La iniciativa que pueda brindarse a las autoridades fiscales locales tiene el potencial de diferenciarse para lograr mejorar el ingreso fiscal del municipio.

El presente artículo está organizado de la siguiente manera: en la siguiente sección presentamos los indicadores económicos y demográficos de la zona fronteriza del estado de Chihuahua; en la tercera sección la metodología empleada; la cuarta contiene los resultados de los modelos estimados; y la quinta las conclusiones.

${ }^{3}$ Guillén y Ziccardi (2004: 25-29) reseñan la evolución del municipio en las constituciones de México. Santana (2000) presenta las características de la reforma de 1983. Santana y Sedas (1999) y Santana (2000) exponen los aspectos incluidos en la reforma al Artículo 115 de 1999. 


\section{Indicadores económicos y demográficos de la zona fronteriza de Chihuahua}

Diferentes estudios reconocen que la región de la frontera norte de México muestra un mayor dinamismo demográfico y económico que otras zonas del país. Entre las causas que se destacan en la literatura se encuentran: la descentralización industrial de 1986 (Arroyo, 2001), la entrada en vigor del Tratado de Libre Comercio (Chiquiar, 2005), las economías de aglomeración (Hanson, 2007; Deichmann, Lall, Redding y Venables, 2008; Mendoza, 2001), el comercio internacional y la inversión extranjera directa (Mendoza, 2005), entre otras. Estas investigaciones enfatizan que la apertura económica, la inversión extranjera y una mayor integración con la economía estadounidense han derivado en un rápido crecimiento del empleo en las ciudades fronterizas.

En el caso particular del estado de Chihuahua, la franja fronteriza está conformada por siete municipios: Ascensión, Guadalupe, Janos, Juárez, Manuel Benavides, Ojinaga y Praxedis G. Guerrero; la actividad económica de la zona está encabezada por el municipio de Juárez. En los siguientes párrafos describiremos la evolución y la estructura demográfica y económica tanto de los municipios fronterizos como de los más importantes del estado de Chihuahua.

El crecimiento de la población en los municipios fronterizos de Chihuahua fue de $27.4 \%$ en el periodo 1995-2005, que contrasta con el de todo el estado, de $16 \%$. Particularmente, el municipio fronterizo de Juárez ha marcado el dinamismo fronterizo de la entidad con un crecimiento poblacional de $29.8 \%$ en 1995 y 2005, por encima del observado en el estado y en cualquiera de sus municipios. Es interesante notar que tal dinamismo, por encima del estatal, también se observa en el municipio no fronterizo de Chihuahua: 20.9\% en esa década. La población en el estado de Chihuahua se concentra principalmente en Juárez (40.5\%) y Chihuahua (23.4\%). La zona fronteriza concentra el $42.7 \%$ de la población de Chihuahua (datos para el año 2005) (cuadro 1).

La frontera norte de Chihuahua muestra también un mayor dinamismo económico. En la industria manufacturera, por ejemplo, el municipio de Juárez participó con el 50.6\% de la producción total estatal (año 2003). En conjunto, los municipios fronterizos concentraron el $51.5 \%$ de la producción manufacturera del estado, y ésta creció $55.5 \%$ en términos reales durante el periodo 1998-2003, con un incre- 
mento muy similar al estatal $(55.8 \%)$. El crecimiento fronterizo de las manufacturas se explica por la dinámica observada en los municipios de Ascensión, Guadalupe y Juárez (cuadro 1).

La industria maquiladora ha sido uno de los factores clave en el desarrollo económico de la región frontera norte de México. En el estado de Chihuahua el 77\% del valor agregado se concentró en Juárez en 2006. En el periodo 2000-2006 el valor agregado de la maquiladora en este municipio aumentó $27.4 \%$ (cuadro 1 ).

$\mathrm{Al}$ igual que la evolución demográfica, el dinamismo económico no ha sido uniforme ni en la zona fronteriza ni en el estado. Resulta evidente que el comportamiento industrial y demográfico experimentado en Juárez ha marcado el observado en la zona fronteriza. Reconocemos que las características particulares de este municipio difieren de las del resto de los municipios fronterizos y no fronterizos, razón por la cual incluimos los efectos individuales de cada uno de ellos como parte del análisis de regresión que se expone más adelante.

Las estructuras y dinámicas demográfica y económica, de acuerdo con Guillén (1996), se traducen en una mayor demanda de servicios públicos, que de no atenderse podría convertirse en una fuente de rezagos sociales y urbanos. Mungaray y Calderón (2001), Fuentes (2001), Cabrero (1999) y Guillén (1990) reconocen que los municipios fronterizos enfrentan una demanda adicional de servicios públicos e infraestructura, que además impone una especial presión sobre las finanzas públicas municipales. Entonces, y de acuerdo con diferentes estudios, el problema fundamental es la falta de recursos de los gobiernos subnacionales fronterizos para enfrentar la demanda adicional por servicios públicos (Margáin, 1999). Si bien es cierto que esta mayor demanda de servicios e infraestructura también se presenta en ciudades muy pobladas y con marcado crecimiento demográfico, es un reto que enfrentan los municipios ubicados en la región frontera norte.

Nuestro postulado fundamental es que la importancia demográfica y económica de la zona fronteriza ha motivado a que los municipios implementen cambios institucionales en materia fiscal, tratando de aprovechar a su máximo su capacidad para responder a la mayor demanda de bienes y servicios públicos. En ese sentido, esperaríamos que la recaudación del impuesto predial de los municipios de la zona fronteriza sea mayor que la de los no fronterizos. 


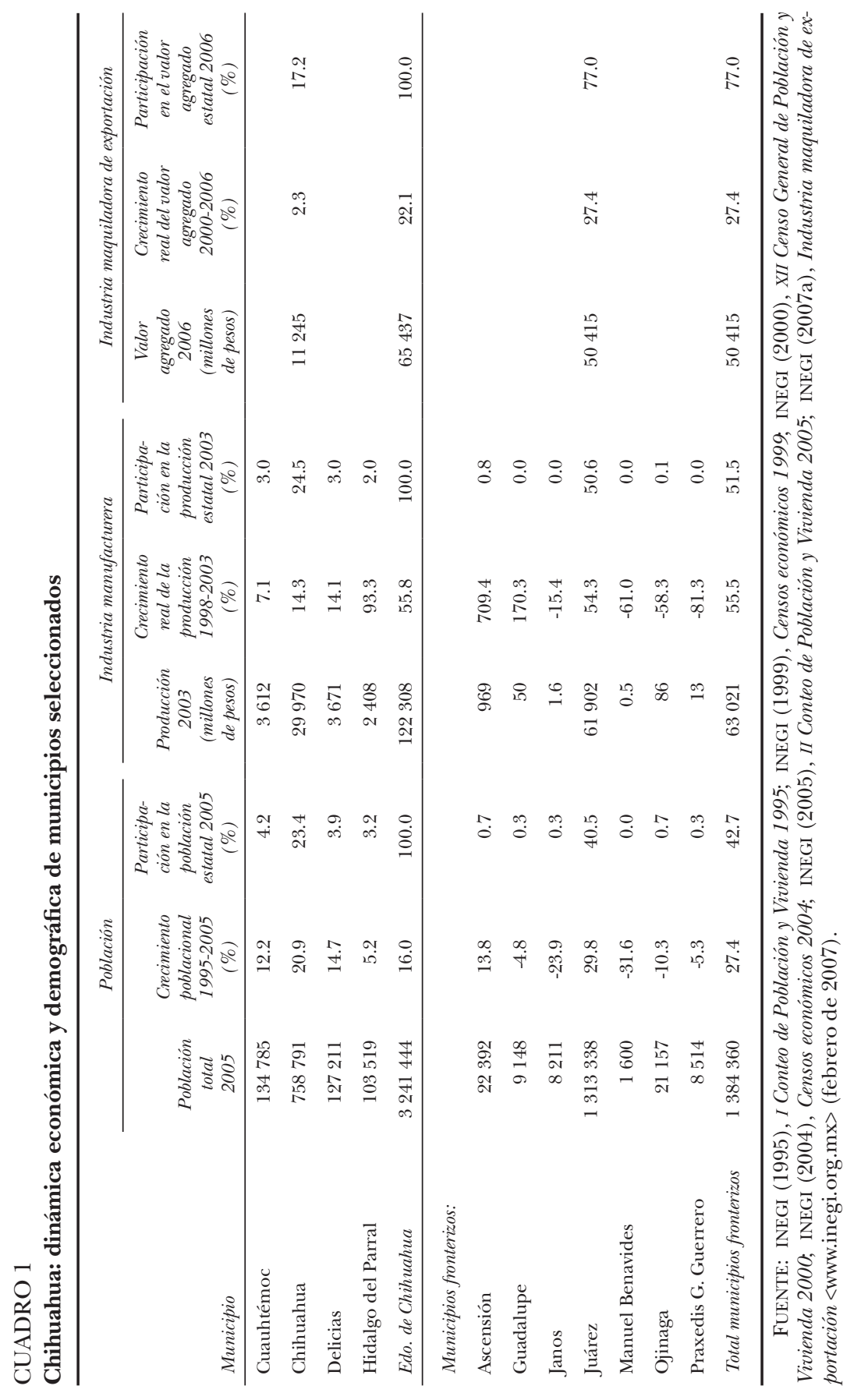




\section{Metodología}

En este artículo especificamos algunos modelos econométricos que nos brindan mayor información sobre el efecto de las diferentes variables que afectan la recaudación del impuesto predial y nos permiten cuantificar el impacto de cada variable independiente en su recaudación, controlando por las variables incluidas en las diferentes especificaciones. Sin embargo, esto no es posible si ésta se comparara entre los municipios. Cuando se compara la recaudación de predial per cápita entre los municipios del estado no es posible determinar si las diferencias se deben a factores económicos (ingreso municipal), a factores fiscales (monto de transferencias recibidas), al grado de urbanización, a la ubicación geográfica, o a diferencias políticas. En particular, ampliamos el estudio de Ibarra y Sotres (2009).

El modelo empírico se fundamenta en la vertiente de las finanzas públicas locales que analiza los determinantes de los ingresos de los gobiernos subnacionales. Los factores que influyen en los ingresos de los gobiernos locales son de corte demográfico, económico y de economía política. Entre las variables demográficas y económicas se encuentran el crecimiento de la población, la migración de población de edad avanzada, los cambios en la pirámide poblacional, la ventaja comparativa de las zonas rurales, y el ingreso per cápita de la población (Kelsey, 1993; Buchanan y Weber, 1982; Henry y Lambert, 1980; Weber y Buchanan, 1980; Vogel y Trost, 1979; Heinze, 1978; Wilford, 1965).

En cuanto a los factores de economía política, existe un grupo de autores que ha vinculado a las instituciones fiscales y las variables políticas con las variaciones en el ingreso gubernamental, además de variables que aproximen la capacidad fiscal y la demanda de bienes provistos por el gobierno (Merrifield, 2000; Feld y Kirchgässner, 2001; Shadbegian, 1999; Alt y Lowry, 1994; Inman, 1979). En particular, el estudio de Merrifield (2000) propone un modelo para estimar el ingreso per cápita por impuestos de los gobiernos estatales en función del área geográfica del estado, el ingreso per cápita, la tasa de crecimiento de la población, el porcentaje de la población mayor de 65 años, el número de alumnos por maestro en las escuelas públicas y variables institucionales y políticas.

Otros estudios que han relacionado el desempeño fiscal de los municipios con variables políticas son los de: Kiewiet y Szakaly (1996), Hagen y Vabo (2005), Galli y Rossi (2002), Feld y Kirchgässner (2001a), 
Allers et al. (2001), Petterson-Lidbom (2001), Shadbegian (1999), Blais y Nadeau (1992), quienes consideran la ideología del gobierno local como determinante; Hagen y Vabo (2005), Feld y Kirchgässner (2001a) y Allers et al. (2001) incluyen la fragmentación del congreso local y del gobierno; Hagen y Vabo (2005) y Allers et al. (2001) toman en cuenta la confluencia política; Galli y Rossi (2002), Rosenberg (1992) y Blais y Nadeau (1992) consideran los ciclos electorales; en tanto que Feld y Kirchgässner (2001b) y Farnham (1990) incluyen como determinante al sistema político asociado a las decisiones colectivas.

La literatura sobre el efecto de las transferencias intergubernamentales ha examinado el impacto de éstas en los ingresos fiscales de los gobiernos locales. Autores como Bartle (1995 y 1996), Stine (1985 y 1994) y Bell y Bowman (1987) han propuesto las siguientes variables como determinantes de la recaudación de impuesto predial: dentro de las demográficas, y con el fin de aproximar las preferencias por impuesto y gasto local de la población, consideran al porcentaje de población en estado de pobreza y a la que es mayor de 65 años y menor de 18 años; para aproximar la capacidad fiscal consideran el valor de la propiedad sujeta de este impuesto y el ingreso per cápita de la población; y tanto las transferencias estatales como las federales.

Con base en los estudios referidos, el modelo empírico que estimamos en este artículo incluye como variables explicativas de la recaudación del impuesto predial per cápita $\left(\mathrm{R}_{\mathrm{it}}\right)$, variables que aproximan la capacidad fiscal, la necesidad fiscal, las transferencias de otros ámbitos de gobierno y variables políticas. De acuerdo con las hipótesis de este artículo, de especial importancia son los efectos institucionales relacionados con los municipios fronterizos.

Para llevar a cabo el análisis de regresión empleamos un panel de datos que combina información en corte transversal de los 67 municipios del estado de Chihuahua, con series de tiempo anual para el periodo 2002-2006. Como anotamos en la sección anterior, los municipios fronterizos de Chihuahua que colindan con Estados Unidos de América son siete: Ascensión, Guadalupe, Janos, Juárez, Manuel Benavides, Ojinaga y Praxedis G. Guerrero. El cuadro 2 presenta la descripción de las variables y las fuentes de información y el cuadro 3 muestra una estadística descriptiva de las variables consideradas en la estimación de los distintos modelos.

Siguiendo a Ibarra y Sotres (2009), cuantificamos la capacidad fiscal valiéndonos del producto interno bruto municipal per cápita 


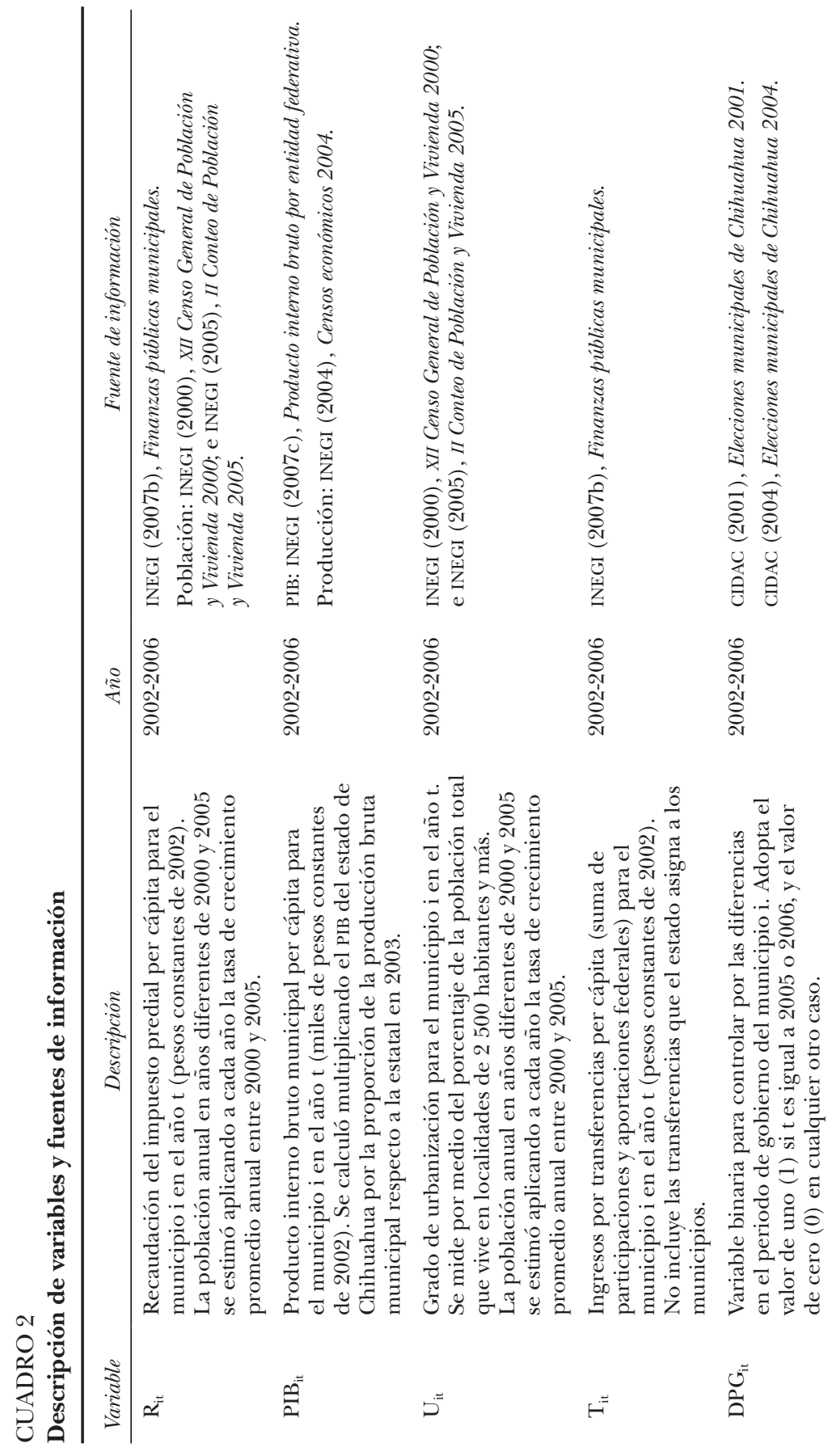


ถุำ

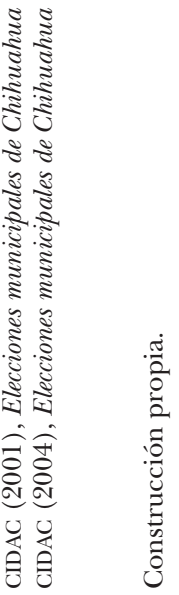

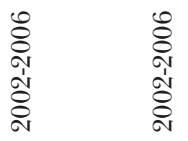

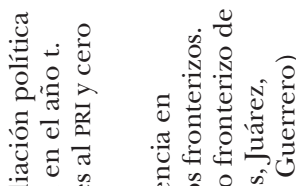

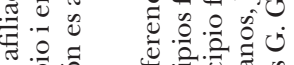

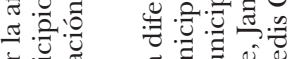

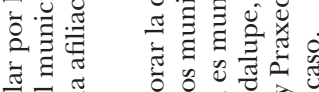

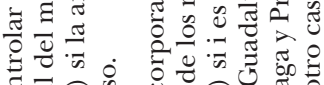

즈유

ช.

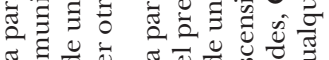

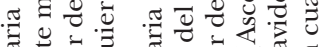

무의

药

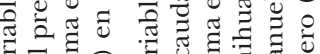

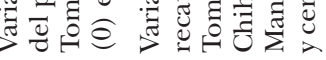

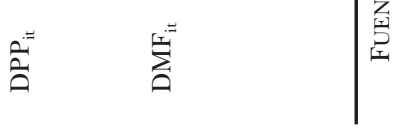




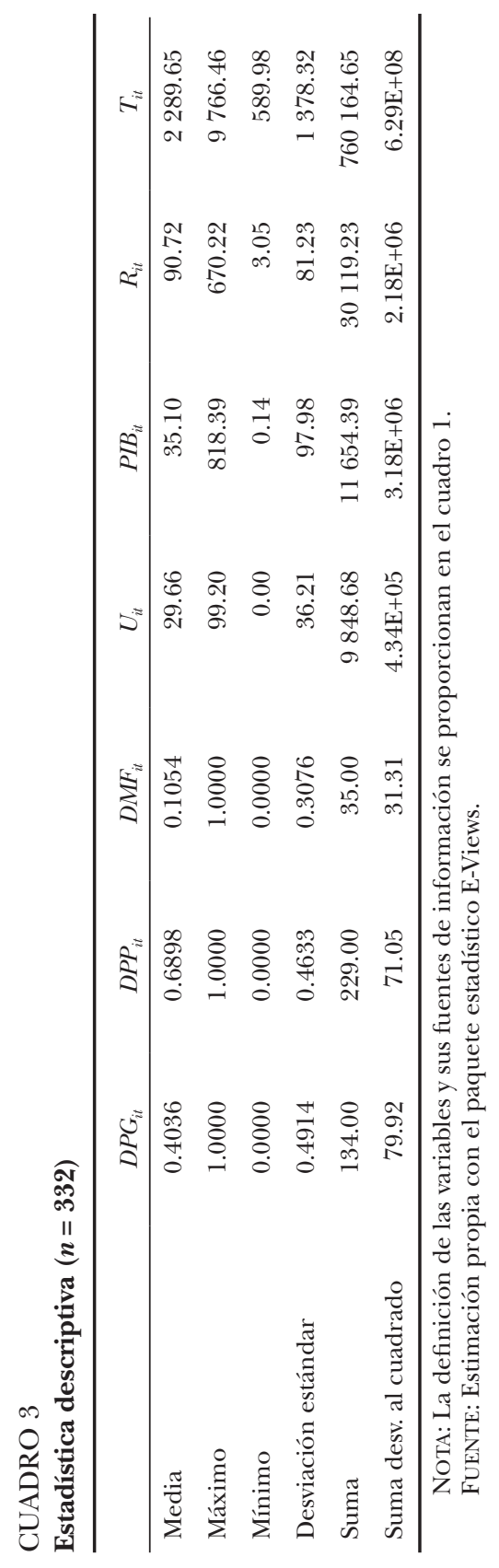


(PIB) $;{ }^{4}$ para la necesidad fiscal empleamos el grado de urbanización (U) ${ }^{5}$ y las transferencias $(\mathrm{T})$, es decir, el monto per cápita que recibieron los municipios por concepto de participaciones y aportaciones federales, excluyendo las transferencias estatales. ${ }^{6}$ Las variables políticas incluyen la identificación del periodo gubernamental (DPG) y la del partido político de afiliación del presidente municipal en turno (DPP). Al igual que Ibarra y Sotres (2009), para identificar los municipios fronterizos usamos dos enfoques: el primero consistió en crear una variable binaria para identificar al conjunto de todos los municipios fronterizos del estado (DMF), y en el segundo creamos una variable binaria para cada municipio fronterizo del estado de Chihuahua. Con el primer enfoque es posible determinar el impacto fronterizo en conjunto, mientras que con el segundo podemos abordar el impacto diferencial de cada municipio fronterizo.

$\mathrm{Al}$ igual que Ibarra y Sotres (2009), en este artículo proponemos tres hipótesis que se derivan de la hipótesis principal. La primera considera las diferencias en las instituciones fiscales a escala municipal. Las reformas constitucionales del Artículo 115 hacen posible que los municipios, en el marco establecido por los poderes ejecutivo y legislativo en el estado, puedan diseñar marcos institucionales distintos en el ámbito fiscal. En particular, con respecto a la recaudación del impuesto predial, los municipios de Chihuahua tienen cierto margen para potencializar la recaudación de dicho impuesto. ${ }^{7}$

${ }^{4}$ Dado que no existen datos sobre el producto municipal, se estimó multiplicando el producto interno bruto estatal por la proporción de la producción bruta total del estado que se realizó en el municipio. El dato de producción bruta total lo tomamos de los Censos económicos 2004 del INEGI y supusimos que la composición en el estado de Chihuahua se mantuvo constante en el periodo de análisis.

${ }^{5} \mathrm{El}$ grado de urbanización de los municipios lo aproximamos con el porcentaje de la población en cada municipio que radica en localidades con más de 2500 personas.

${ }^{6}$ Los municipios del estado de Chihuahua reciben transferencias federales y estatales. La variable de transferencias en este artículo sólo incluye las federales para evitar la causalidad de la recaudación del predial sobre las transferencias estatales. El Artículo 315 del Código Fiscal del Estado de Chihuahua especifica que 50\% del ingreso por impuestos estatales no destinados a un fin específico se distribuye de acuerdo con la recaudación del impuesto predial; véase <http://www.ordenjuridico.gob.mx/EnFe/ CHIHUAHUA/legislativo.php > (abril de 2009). Ibarra y Sotres (2009) no incluyeron las transferencias en sus estimaciones debido a que causaba un problema de multicolinealidad severo.

${ }^{7}$ El Artículo 6 de la Ley de Catastro del Estado de Chihuahua contiene las atribuciones de la autoridad catastral municipal: diseñar, integrar, implantar, operar y actualizar el catastro en el ámbito de su competencia; formular y actualizar la zonificación catastral de los predios; determinar el valor catastral de los predios; formular y proponer las tablas de valores unitarios para el suelo y la construcción que servirán para determi- 
Hipótesis 1. Las diferencias institucionales en el ámbito fiscal ayudan a explicar las variaciones en la recaudación del impuesto predial entre los municipios de Chihuahua.

La segunda hipótesis considera, específicamente, las diferencias institucionales de los municipios de la zona fronteriza de Chihuahua.

Hipótesis 2. Las diferencias institucionales en el ámbito fiscal en los municipios de la zona fronteriza de Chihuahua ayudan a explicar las variaciones en la recaudación del impuesto predial entre los municipios de ese estado.

La tercera hipótesis compara la recaudación del impuesto predial de los municipios fronterizos con la de los no fronterizos, controlando por la capacidad, la necesidad fiscal, el monto de transferencias y las variables políticas.

Hipótesis 3. La recaudación por impuesto predial en los municipios fronterizos es mayor que la de los municipios no fronterizos de Chihuahua.

Los modelos que se explican a continuación tienen como base a Ibarra y Sotres (2009). El Modelo 1 es el de referencia para los distintos casos:

$$
\mathrm{R}_{\mathrm{it}}=\alpha+\theta \mathrm{PIB}_{\mathrm{it}}+\tau \mathrm{U}_{\mathrm{it}}+\gamma \mathrm{T}_{\mathrm{it}}+\delta_{1} \mathrm{DPG}_{\mathrm{it}}+\delta_{2} \mathrm{DPP}_{\mathrm{it}}+\varepsilon_{\mathrm{it}},
$$

donde $\mathrm{i}=1, \ldots, 67$ representa el municipio, $\mathrm{t}=2002, \ldots, 2006 \mathrm{el}$ año y $\varepsilon_{\mathrm{it}}$ representa el término del error. El Modelo 1 es el modelo restringido para efectos de las pruebas de hipótesis que se describen adelante. El modelo no restringido para la Hipótesis 1 incorpora las diferencias institucionales entre los municipios del estado. Denotando como $\mathfrak{I}$ = \{Ascensión, Guadalupe, Janos, Juárez, Manuel Benavides, Ojinaga y Praxedis G. Guerrero\} al conjunto de municipios que componen la zona fronteriza del estado de Chihuahua, especificamos al Modelo 2 como:

$$
\mathrm{R}_{\mathrm{it}}=\alpha_{\mathrm{i} \notin \mathfrak{S}}+\beta_{\mathrm{i} \in \mathfrak{I}}+\theta \mathrm{PIB}_{\mathrm{it}}+\tau \mathrm{U}_{\mathrm{it}}+\gamma \mathrm{T}_{\mathrm{it}}+\delta_{1} \mathrm{DPG}_{\mathrm{it}}+\delta_{2} \mathrm{DPP}_{\mathrm{it}}+\varepsilon_{\mathrm{it}} .
$$

El término constante para cada municipio fronterizo es $\beta_{\mathrm{i}}, \mathrm{i} \in \mathfrak{I}$, mientras que para cada municipio no fronterizo es $\alpha_{\mathrm{i}}, \mathrm{i} \notin \mathfrak{I}$. Dado que estamos controlando por las diferencias en capacidad y necesidad

nar los valores catastrales y serán la base para el cálculo del impuesto predial, entre otros. El Artículo 149 del Código Municipal del Estado de Chihuahua contiene las tasas y tarifas que sirven como base para el cálculo del impuesto predial, y muestra la forma de cálculo de este impuesto. 
fiscal, por el monto de transferencias, así como por diferencias de tipo político entre los municipios, el término constante puede capturar las diferencias institucionales y organizacionales de los municipios que ayudan a explicar las variaciones y diferencias en la recaudación del impuesto predial en el estado. A pesar de que pertenecen a una misma entidad federativa y enfrentan, por ejemplo, el mismo marco legal en el ámbito fiscal relacionado con el impuesto predial y con el catastro, los municipios del estado de Chihuahua tienen cierto margen de maniobra para mejorar su recaudación. ${ }^{8}$

Para probar la Hipótesis 1 empleamos los Modelos 1 y 2 con el objeto de determinar la significancia de los efectos de grupo (Greene, 2008: 197). Si las características institucionales en los municipios ayudasen a explicar las variaciones en la recaudación del impuesto predial, entonces habría una diferencia significativa en la suma de los errores al cuadrado entre dichos modelos. La hipótesis nula para este caso es que los términos constantes en el Modelo 2 sean iguales para todos los municipios considerados $\left(\alpha_{1}=\alpha_{2}=\ldots=\alpha_{60}=\beta_{\text {Ascensión }}=\beta_{\text {Guadalupe }}=\ldots=\right.$ $\beta_{\text {P. G. Guerrero). }}$.

Con la Hipótesis 2 queremos probar si las diferencias institucionales en todos los municipios fronterizos de Chihuahua ayudan a explicar las variaciones en la recaudación del predial. Identificamos los municipios fronterizos en los modelos empíricos de dos formas: definimos la variable binaria $\mathrm{DMF}_{\mathrm{it}}$ (toma el valor de 1 para todo municipio fronterizo y cero en cualquier otro caso), y estimamos un término constante diferente para cada municipio fronterizo.

El Modelo 3, que incorpora la variable $\mathrm{DMF}_{\mathrm{it}}$, considera también los efectos de las variables independientes de los modelos anteriores e identifica a todos los municipios fronterizos con una sola variable dicotómica:

$$
\mathrm{R}_{\mathrm{it}}=\alpha+\beta \mathrm{DMF}_{\mathrm{it}}+\theta \mathrm{PIB}_{\mathrm{it}}+\tau \mathrm{U}_{\mathrm{it}}+\gamma \mathrm{T}_{\mathrm{it}}+\delta_{1} \mathrm{DPG}_{\mathrm{it}}+\delta_{2} \mathrm{DPP}_{\mathrm{it}}+\varepsilon_{\mathrm{it}} .
$$

Este modelo supone que la diferencia en la recaudación de predial entre los municipios fronterizos y no fronterizos del estado, una vez que se controla por diferencias en el resto de las variables independientes, son capturadas por el parámetro $\beta$. Si $\beta$ es positiva, entonces habrá evidencia de que la recaudación del predial de los municipios fronterizos del estado de Chihuahua es mayor que la del resto de los 
municipios de ese estado. Por otro lado, si ese parámetro fuera cero, entonces habría evidencia de que no hay diferencias significativas en la recaudación del predial entre los municipios fronterizos y no fronterizos de Chihuahua.

El Modelo 4 mantiene el supuesto de que los parámetros de las variables independientes son iguales entre los municipios de Chihuahua y a través del tiempo, y a diferencia del Modelo 3, considera un término constante diferente para cada municipio fronterizo.

$$
\mathrm{R}_{\mathrm{it}}=\alpha+\beta_{\mathrm{i} \in \mathfrak{I}}+\theta \mathrm{PIB}_{\mathrm{it}}+\tau \mathrm{U}_{\mathrm{it}}+\gamma \mathrm{T}_{\mathrm{it}}+\delta_{1} \mathrm{DPG}_{\mathrm{it}}+\delta_{2} \mathrm{DPP}_{\mathrm{it}}+\varepsilon_{\mathrm{it}} .
$$

El término constante $\beta_{\mathrm{i}_{\in \mathcal{I}}}$ captura los efectos de aquellas variables que se omiten en el modelo y que son específicas para cada municipio fronterizo, particularmente las diferencias institucionales en el ámbito fiscal que explican las variaciones en la recaudación del impuesto predial. El término constante para los municipios no fronterizos es igual a $\alpha$, en tanto que para el municipio fronterizo i $\in \mathfrak{I}$, el intercepto es igual a $\alpha+\beta_{\mathrm{i}}$. La hipótesis nula para probar la Hipótesis 2 usando el Modelo 4 es que $\beta_{\mathrm{i}}$ sea igual a cero para los siete municipios fronterizos del estado. Tales restricciones nos indicarían que no hay diferencia en la recaudación del predial de cada municipio fronterizo con el resto de municipios del estado de Chihuahua. $\mathrm{Al}$ sustituir estas restricciones en los parámetros en el Modelo 4 se obtiene el Modelo 1 de la expresión [1]. Así, para construir el estadístico de prueba de la Hipótesis 2, el Modelo 1 corresponde al modelo restringido y el Modelo 4 al no restringido.

Para determinar estadísticamente si hay evidencia de que la recaudación en la zona fronteriza de Chihuahua es mayor con relación a los municipios no fronterizos en ese estado, la Hipótesis 3, estimamos además el Modelo 5:

$$
\mathrm{R}_{\mathrm{it}}=\alpha_{\mathrm{i} \notin \mathfrak{S}}+\beta \mathrm{DMF}_{\mathrm{it}}+\theta \mathrm{PIB}_{\mathrm{it}}+\tau \mathrm{U}_{\mathrm{it}}+\gamma \mathrm{T}_{\mathrm{it}}+\delta_{1} \mathrm{DPG}_{\mathrm{it}}+\delta_{2} \mathrm{DPP}_{\mathrm{it}}+\varepsilon_{\mathrm{it}} .[5]
$$

En este modelo el término constante de los municipios fronterizos es $\beta$, en tanto que el de cada municipio no fronterizo es $\alpha_{i}$, para $i \notin \mathfrak{I}$. Para determinar si existe evidencia en favor de la Hipótesis 3 realizamos cuatro ejercicios de inferencia estadística:

I. Con el Modelo 3 probamos si $\beta$ es positiva. Como el término constante de los municipios fronterizos en dicho modelo es $\alpha$ 
$+\beta$, y el de los municipios no fronterizos es $\alpha$, si $\beta$ es positiva entonces la recaudación del predial de los municipios fronterizos será mayor que la recaudación de los no fronterizos en Chihuahua.

II. A partir del Modelo 4 planteamos como hipótesis alternativas que $\beta_{i \in \mathfrak{S}}>0$. Si se rechazan las hipótesis nulas para cada caso, habrá evidencia de que, considerando las diferencias políticas, el monto de las transferencias, la capacidad y la necesidad fiscal, la recaudación del impuesto predial de cada municipio fronterizo es mayor a la recaudación de los municipios no fronterizos del estado. Esto es así, pues si $\beta_{\mathrm{i}_{\in \mathfrak{S}}}>0$ entonces $\alpha+$ $\beta_{\mathrm{i} \in \mathfrak{S}}>\alpha$. El parámetro $\alpha$ en el Modelo 4 representa la constante de los municipios no fronterizos, en tanto que $\alpha+\beta_{\mathrm{i} \in \mathfrak{S}}$ es el término constante para cada uno de los municipios fronterizos.

III. Los Modelos 3 y 4 suponen que el término constante es igual para todos los municipios no fronterizos. Con el Modelo 5, que supone una constante diferente para cada municipio no fronterizo, para que la recaudación del predial de los municipios fronterizos sea mayor que la de cada uno de los no fronterizos se debería cumplir que $\beta>\alpha_{i \notin \mathfrak{I}}$. En este caso realizamos 60 pruebas de hipótesis para determinar si el parámetro $\beta$ es mayor que cada uno de los parámetros constantes de los municipios no fronterizos.

IV. Por último, usamos el Modelo 2 para probar si el término constante de cada municipio fronterizo es diferente del de cada municipio no fronterizo: $\beta_{i_{\in} \mathfrak{I}}>\alpha_{i_{\notin} \mathfrak{S}}$ para cada $i \in \mathfrak{I}$ y cada $\mathrm{i} \notin \mathfrak{I}$.

Dada la estrategia de inducción estadística que empleamos en este artículo, elegimos como método de estimación el de mínimos cuadrados ordinarios combinados (pooled regression) para los Modelos 1, 3 y 4. Los Modelos 2 y 5 fueron estimados empleando el enfoque de efectos fijos y el método de mínimos cuadrados con variables dicotómicas para los diferentes grupos (least squares dummy variable model) (Greene, 2008: 194-196).

\section{Resultados}

El cuadro 4 contiene los resultados obtenidos en la estimación de los cinco modelos propuestos en la sección anterior. La recaudación de 


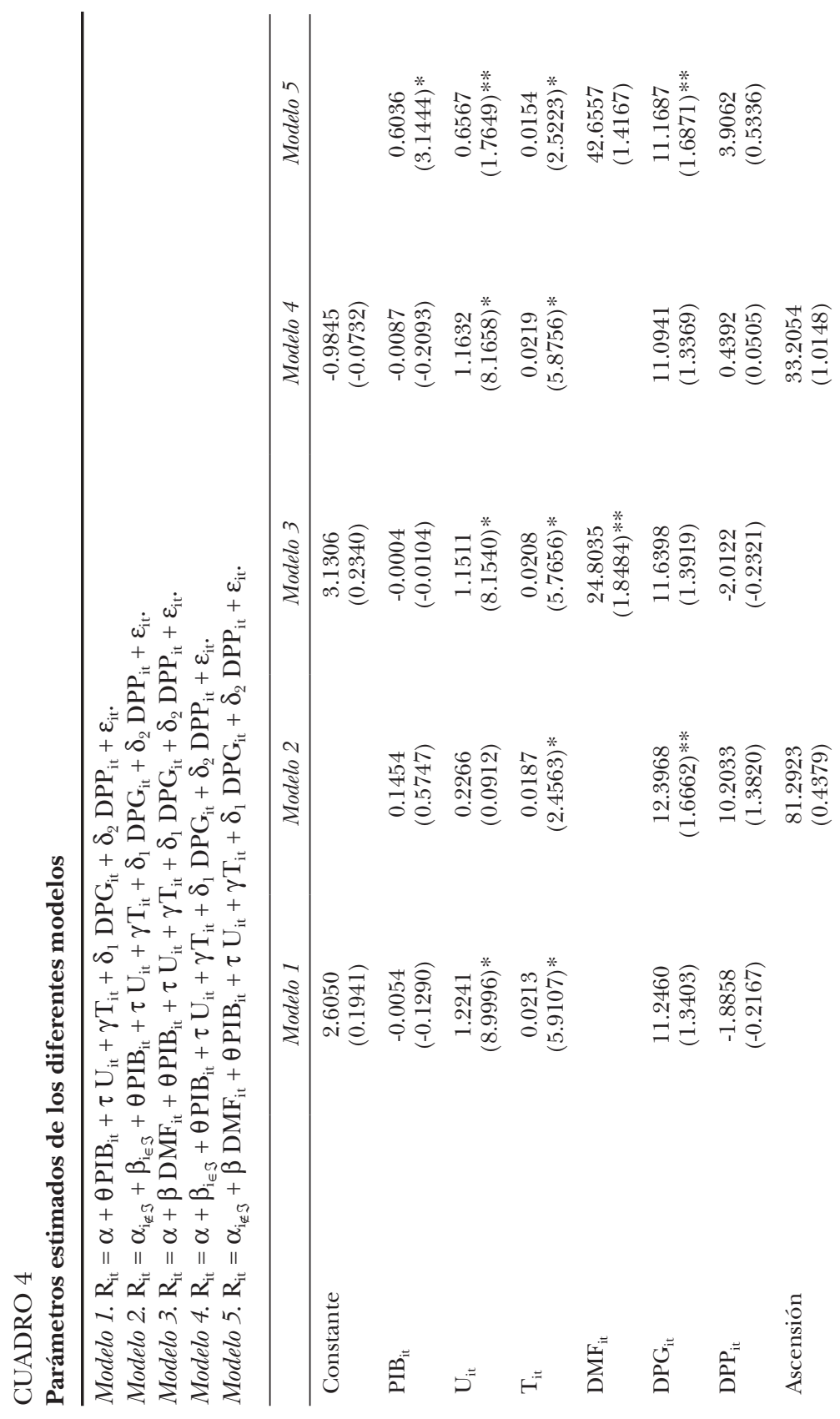




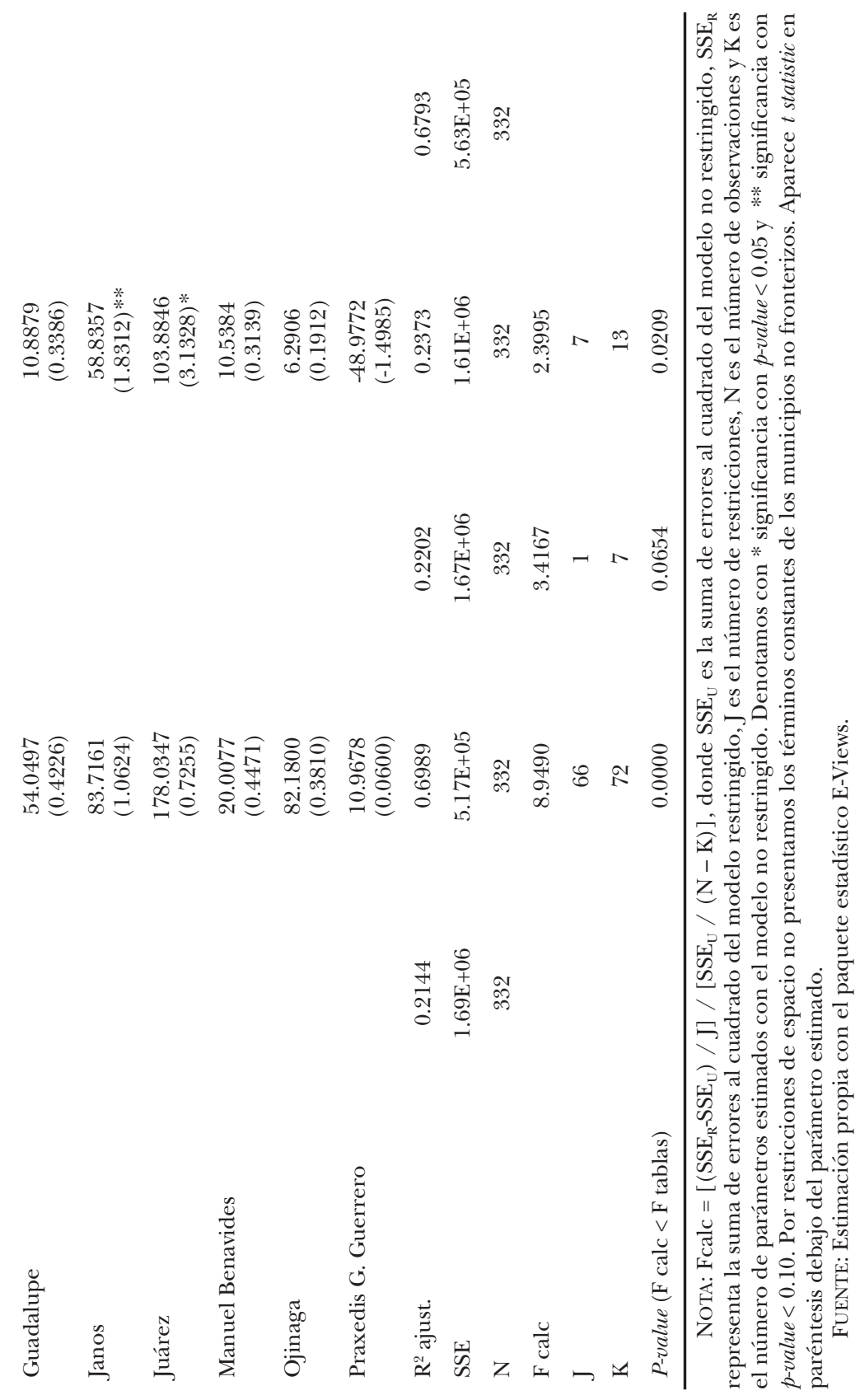


predial per cápita $\left(\mathrm{R}_{\mathrm{it}}\right)$ resultó con una relación directa con el PIB municipal per cápita $\left(\mathrm{PIB}_{\mathrm{it}}\right)$ en los Modelos 2 y 5 , y únicamente en este último es estadísticamente significativa. Si bien todos los modelos estimados imponen restricciones en los parámetros de las variables independientes, el Modelo 2 supone un término constante diferente para cada municipio de Chihuahua, y el Modelo 5 supone una constante diferente para cada municipio no fronterizo. Estos dos modelos son los que resultaron con mayor coeficiente de determinación $\left(\mathrm{R}^{2}\right)$ entre los cinco estimados. En esos casos, la recaudación del predial per cápita aumentaría en 0.15 pesos, de acuerdo con el Modelo 2, o en 0.60 pesos, de acuerdo con el Modelo 5, por cada mil pesos que se incremente la producción municipal per cápita de los municipios de Chihuahua.

La variable $\mathrm{U}_{\mathrm{it}}$, incluida para controlar por el grado de necesidad fiscal municipal, muestra una relación directa y estadísticamente significativa en todos los modelos estimados, excepto en el Modelo 2.

Todos los modelos estimados muestran una relación directa y estadísticamente significativa entre el monto de transferencias per cápita y la recaudación de predial per cápita en los municipios de Chihuahua. Este resultado es interesante a la luz de los efectos de las transferencias federales en los ingresos de los gobiernos municipales. Este hallazgo sugiere que el aumento en el monto de transferencias no se traduce en una reducción de impuestos municipales, tal como lo sugiere la literatura relacionada (Stine, 1985). Creemos que el efecto de las transferencias condicionadas y no condicionadas sobre los ingresos municipales en México requiere de mayor estudio.

El efecto marginal de las transferencias en la recaudación del predial en todos los modelos es sorprendentemente consistente: la recaudación del predial per cápita aumenta en 2 pesos por cada 100 pesos de incremento de las transferencias. Es pertinente advertir que este resultado, aunque interesante, debe ser interpretado con cuidado, ya que en este artículo se ha supuesto que dicho efecto marginal es igual en todos los municipios de Chihuahua durante el periodo de análisis. Además, no se ha separado el efecto diferencial que sobre la recaudación del predial pudieran tener las participaciones y las aportaciones federales. La figura de transferencias que usamos en este artículo agrega ambos renglones.

Los resultados muestran que el parámetro estimado de la variable que identifica los periodos de gobierno $\left(\mathrm{DPG}_{\mathrm{it}}\right)$ incluidos en la muestra, 2002-2004 y 2005-2006, es positivo en los cinco modelos estimados, y en dos de ellos (Modelos 2 y 5) la relación es significativa desde el pun- 
to de vista estadístico. Este resultado implica que la recaudación del predial per cápita en las administraciones municipales concluidas en 2006 es mayor que la recaudación de las administraciones de 2002-2004. El parámetro estimado en el Modelo 2 indica que la recaudación por habitante fue mayor en 12.4 pesos. Este resultado pudo haber sido causado por la puesta en marcha del Pimcat hacia finales de 2004. De acuerdo con sus registros, en promedio los municipios registraron un aumento del $16.4 \%$ en la recaudación del impuesto predial con respecto al año anterior a su implementación. El hecho de que a partir del $1^{\circ}$ de enero de 2005 se actualizara de manera general el valor catastral de los predios de acuerdo con lo estipulado en el Artículo Segundo Transitorio de la Ley de Catastro del Estado de Chihuahua ${ }^{9}$ también contribuyó al incremento en la recaudación del predial en ese periodo de gobierno.

El parámetro estimado de la variable de control para la afiliación política del presidente municipal $\left(\mathrm{DPP}_{\mathrm{it}}\right)$ no es consistente ni en cuanto a su valor, ni en cuanto a su signo. Adicionalmente, en todos los modelos esta variable no es estadísticamente significativa.

Para probar la hipótesis de que el marco institucional a escala municipal tiene un papel significativo para explicar las diferencias en la recaudación del predial per cápita entre los municipios del estado, presentamos la prueba de Chow, imponiendo la restricción de que todos los parámetros constantes $\left(\alpha_{\mathrm{i}_{\notin} \mathfrak{S}}, \beta_{\mathrm{i}_{\in} \mathfrak{I}}\right)$ de los municipios chihuahuenses en el Modelo 2 son iguales. El estadístico de prueba resultante, que se reporta en la línea $F$ calc del cuadro 4 para el Modelo 2, fue 8.95. Al rechazar la hipótesis nula de que los parámetros constantes de los municipios en el Modelo 2 son iguales, encontramos evidencia de que el marco institucional municipal causa diferencias significativas en la recaudación del impuesto predial per cápita. Creemos que este resultado es un indicio de que las reformas constitucionales del Artículo 115 han posibilitado a los municipios de un mismo estado a enfrentar un marco institucional diferente en el ámbito fiscal, y que tales diferencias provocan que la cuantía de la recaudación del impuesto predial per cápita sea también distinta para los municipios en igualdad de circunstancias.

Para probar la segunda hipótesis de este artículo trabajamos con los Modelos 3 y 4. En el primer caso se incluye una sola variable para identificar a los municipios fronterizos, en tanto que en el segundo se

${ }_{9}$ Publicado en el Periódico Oficial del Estado, núm. 104, 29 de diciembre de 2004. 
especifica un término constante para cada municipio ubicado en la zona fronteriza del norte de Chihuahua. A partir del Modelo 3, en la ecuación [3], debemos probar si $\beta$ es igual a cero, en tanto que con el Modelo 4, en la ecuación [4], debemos probar en conjunto si $\beta_{\mathrm{i}}=0$ para cada municipio fronterizo $(i \in \mathfrak{I})$. En ambos casos, al imponer las restricciones indicadas por las hipótesis nulas para los parámetros, resulta que el restringido es el Modelo 1, en la ecuación [1]. En el cuadro 4 aparece el valor del estadístico $\mathrm{F}$ de prueba en la línea $F$ calc para cada uno de los casos. El estadístico calculado es 3.42 con relación al Modelo 3 y 2.40 para el Modelo 4. En el primer caso se puede rechazar la hipótesis nula con una significancia menor al 10\% (p-value 0.0654), y en el segundo con una menor al 5\% (p-value 0.0209). De esa forma, al rechazar ambas hipótesis nulas, se confirma la evidencia de que las J-restricciones impuestas a los parámetros poblacionales en los modelos no restringidos en cada caso no son verdaderas. Esto implica que las variables que identifican a los municipios fronterizos, ya sea en conjunto o en forma individual, deben incluirse en el modelo para explicar las variaciones en la recaudación del impuesto predial per cápita de los municipios del estado de Chihuahua. Por tanto, las consideraciones regionales fronterizas que motivan diferencias institucionales en el ámbito fiscal son relevantes en la explicación de las variaciones en la recaudación del impuesto predial per cápita.

La tercera hipótesis consiste en determinar si existen diferencias significativas en la recaudación del impuesto predial per cápita de los municipios fronterizos en comparación con los no fronterizos. Consideramos cuatro variantes para este propósito. La primera consiste en averiguar si hay evidencia de que, a partir del Modelo 3, el parámetro poblacional de la variable que identifica a los municipios fronterizos, $\beta$, es positivo. Con el estadístico t de prueba igual a 1.8484, el p-value correspondiente a 325 grados de libertad es 0.0327 . Por tanto, tenemos evidencia de que, controlando por la capacidad y necesidad fiscal, por el monto de las transferencias, así como por las variables políticas, la recaudación del impuesto predial per cápita de los municipios fronterizos es mayor que la de los municipios no fronterizos del estado de Chihuahua. El valor estimado de $\beta$ en el Modelo 3, de 24.8 pesos de 2002, brinda una figura numérica de la diferencia en recaudación del predial per cápita entre los municipios fronterizos y no fronterizos.

En la segunda variante realizamos pruebas de hipótesis individuales para determinar si existe evidencia estadística de que los parámetros $\beta_{\mathrm{i} \in \mathfrak{I}}$ en el Modelo 4 son positivos para cada municipio fronterizo. Usan- 
do los resultados de dicho modelo, que aparecen en el cuadro 4, se puede apreciar que los parámetros estimados para seis de los siete municipios fronterizos son positivos (Ascensión, Guadalupe, Janos, Juárez, Manuel Benavides y Ojinaga), aunque para Praxedis G. Guerrero resultó negativo. Con relación a los primeros, los estadísticos t de prueba para Janos (1.8312) y Juárez (3.1328), con una significancia menor al 10 y $5 \%$ respectivamente, rechazan la hipótesis nula de que el parámetro poblacional es igual o menor a cero, en favor de la alternativa de que el parámetro es positivo. Para estos dos municipios existe evidencia de que, controlando por las diferencias políticas, el monto de transferencias per cápita, la capacidad y necesidad fiscal, su recaudación de predial per cápita es significativamente mayor que la de los municipios no fronterizos. Los parámetros estimados proporcionan una aproximación de tal diferencia. En pesos de 2002, las diferencias estimadas son de 58.84 pesos para Janos y de 103.88 pesos para Juárez.

La tercera variante consiste en averiguar si la recaudación per cápita de los municipios de la zona fronteriza norte de Chihuahua es mayor a la de cada municipio no fronterizo del estado. A partir del Modelo 5, la hipótesis nula es que no hay diferencia entre la recaudación per cápita de los municipios fronterizos en conjunto y cada uno de los no fronterizos: $\beta-\alpha_{1 \notin \mathfrak{S}}=0$, para cada i que no es elemento de $\mathfrak{I}$. La estimación del Modelo 5 y la matriz de varianza-covarianza de los parámetros estimados con dicho modelo nos permitieron calcular los estadísticos de prueba que aparecen en la última columna del cuadro 5 . En 34 de los 60 casos se rechaza la hipótesis nula, con lo que hay evidencia estadística de que la recaudación de los municipios fronterizos en conjunto es mayor que la de esos 34 municipios no fronterizos. Aunque se rechaza la hipótesis para más de la mitad de los casos, este resultado no nos permite concluir que, controlando por las diferencias en las variables políticas, $\mathrm{PIB}_{\mathrm{it}}, \mathrm{T}_{\mathrm{it}} \mathrm{y} \mathrm{U}_{\mathrm{it}}$, la recaudación del predial per cápita en los municipios fronterizos sea mayor que la de cada uno de los municipios no fronterizos de Chihuahua.

Finalmente, con la cuarta variante el propósito es determinar si, considerando las diferencias políticas, de capacidad y necesidad fiscal, y el monto de transferencias per cápita, la recaudación de predial per cápita de cada municipio ubicado en la zona fronteriza del norte es mayor que la de cada municipio no fronterizo de Chihuahua. La prueba de hipótesis consiste en valorar estadísticamente las diferencias entre los parámetros constantes de los municipios fronterizos y los no 
fronterizos. Usando los resultados del Modelo 2 calculamos el estadístico t de prueba que se muestra en el cuadro 5.

Como se puede apreciar, y consistente con el resultado que comentamos en el párrafo anterior, no podemos afirmar que la recaudación del impuesto predial de cada municipio fronterizo sea mayor que la de cada municipio no fronterizo. A pesar de ese resultado general, es interesante la evidencia contrastante de cuatro municipios fronterizos: Janos, Juárez, Ojinaga y Praxedis G. Guerrero. Por un lado, los resultados indican que la recaudación per cápita por predial de Janos es mayor a la de 23 municipios no fronterizos, mientras que la de Juárez es mayor que la de 15 municipios no fronterizos. Por otro lado, la recaudación del predial per cápita de Ojinaga es únicamente mayor que la de dos municipios no fronterizos, en tanto que para el caso de Praxedis G. Guerrero no es posible rechazar la hipótesis nula en ningún caso.

Los resultados muestran también que hay una serie de municipios no fronterizos para los que no es posible rechazar la hipótesis de esta cuarta variante. Tal es el caso de poco más de la tercera parte de los municipios no fronterizos (25 municipios). Esta lista no sólo incluye los municipios más poblados y desarrollados de Chihuahua, como Cuauhtémoc, Chihuahua y Delicias, sino también a municipios con un menor grado de desarrollo económico. Con respecto al municipio de Chihuahua, es interesante notar que los estadísticos de prueba respecto a todos los municipios fronterizos son negativos (aunque en ningún caso esa diferencia sea significativa).

\section{Conclusiones}

Con base en el estudio de Ibarra y Sotres (2009), en este artículo hemos estimado algunos modelos de recaudación del impuesto predial per cápita empleando un panel de datos compuesto con información de 67 municipios de Chihuahua para el periodo 2002-2006. En atención a la literatura relacionada, los modelos explicaron las variaciones de la recaudación del predial per cápita como una función de la capacidad fiscal, la necesidad fiscal, las variables políticas e institucionales, y el monto de transferencias per cápita. Los resultados que encontramos son consistentes con los que se obtuvieron con datos de los municipios de Tamaulipas (Ibarra y Sotres, 2009): que las características regionales e institucionales ayudan a explicar las diferencias de recaudación del predial entre los municipios. 


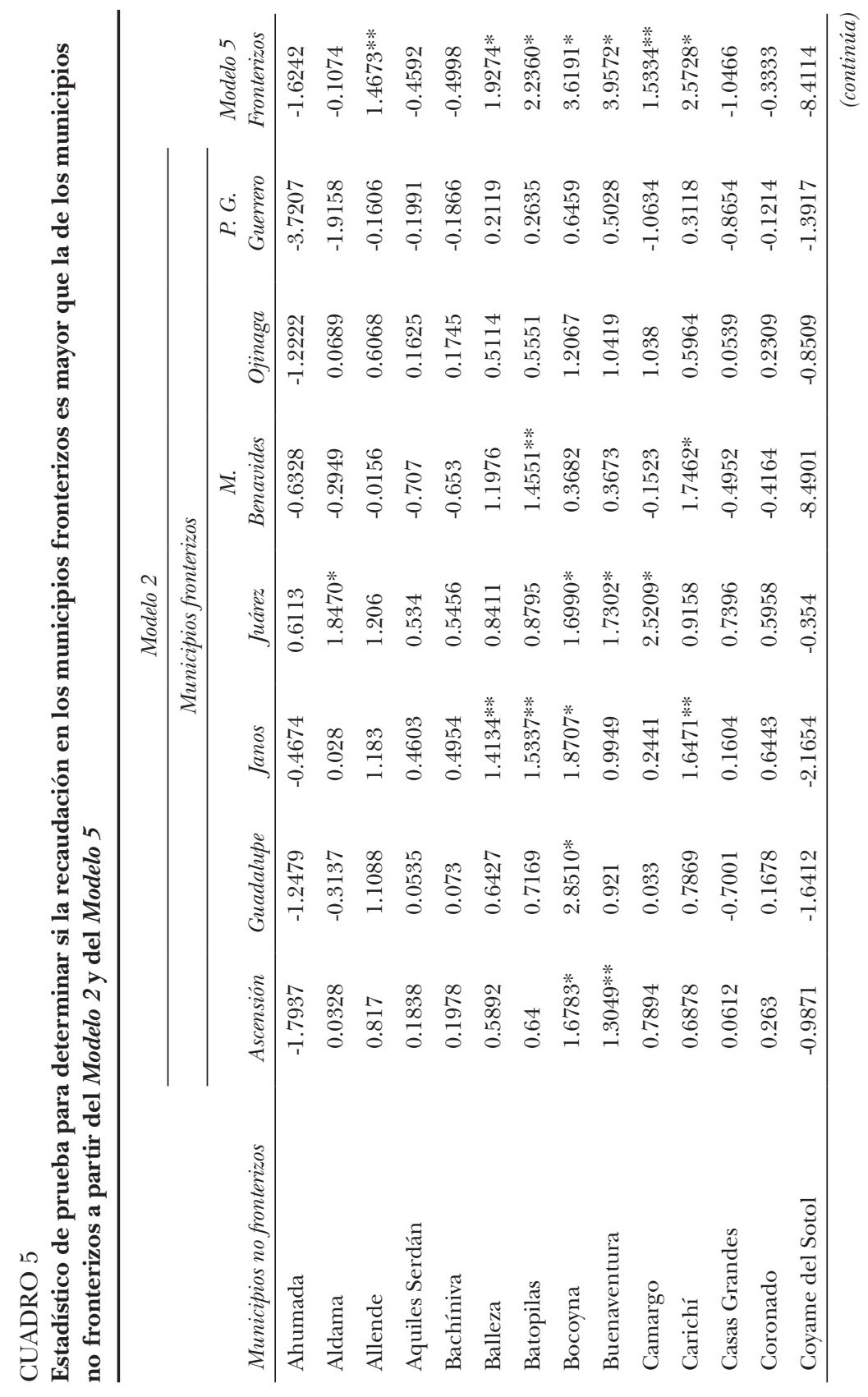




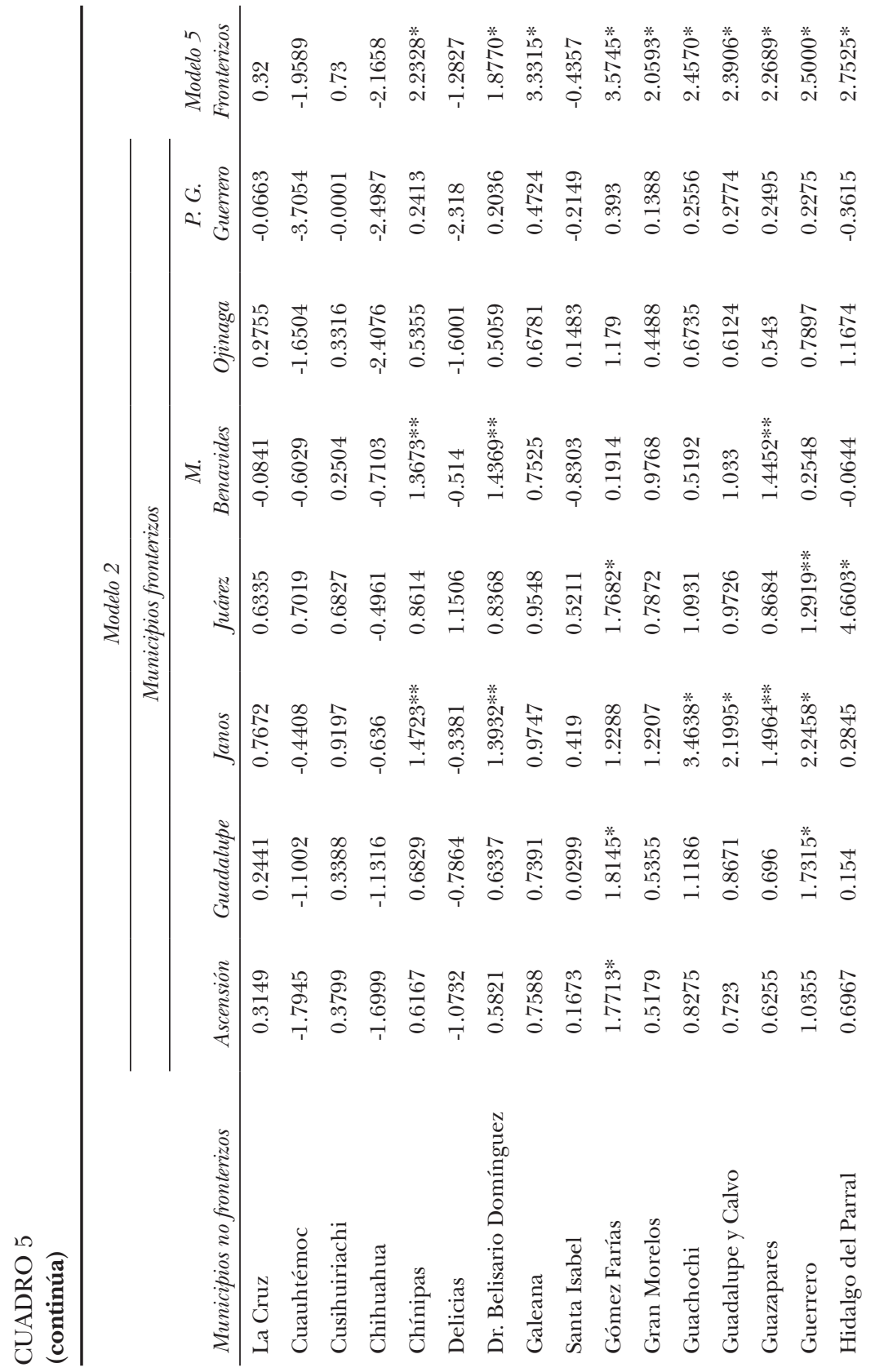




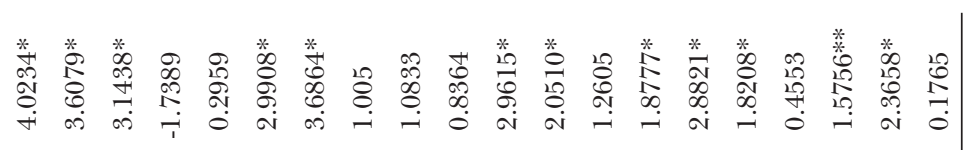

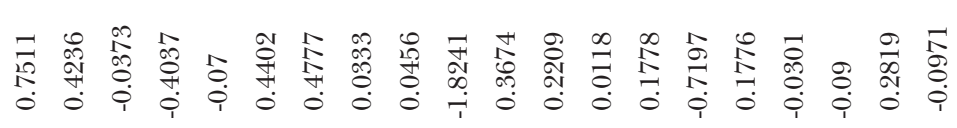

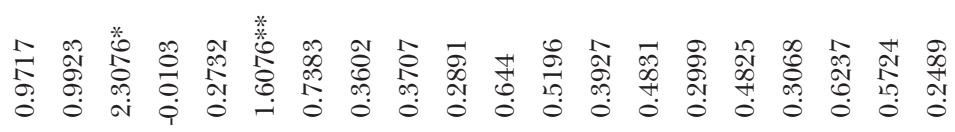

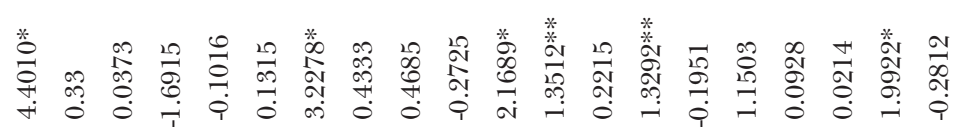

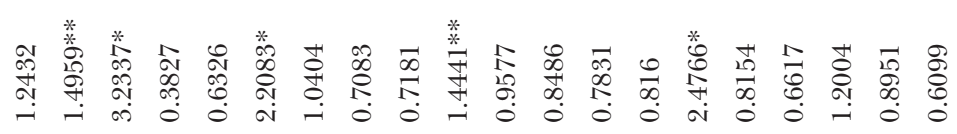

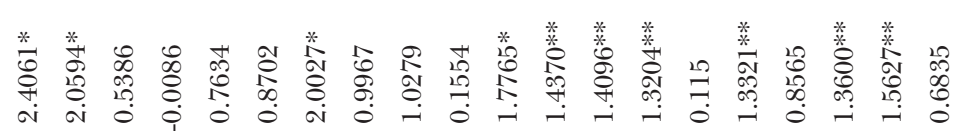

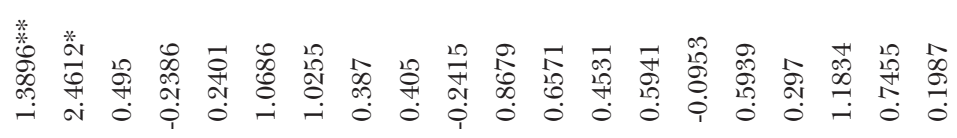

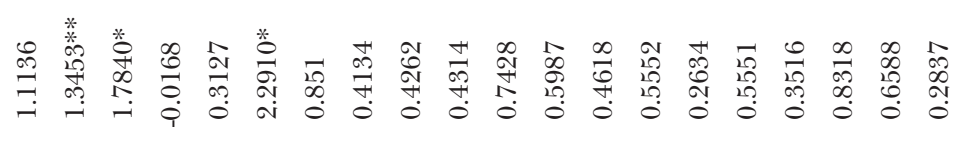

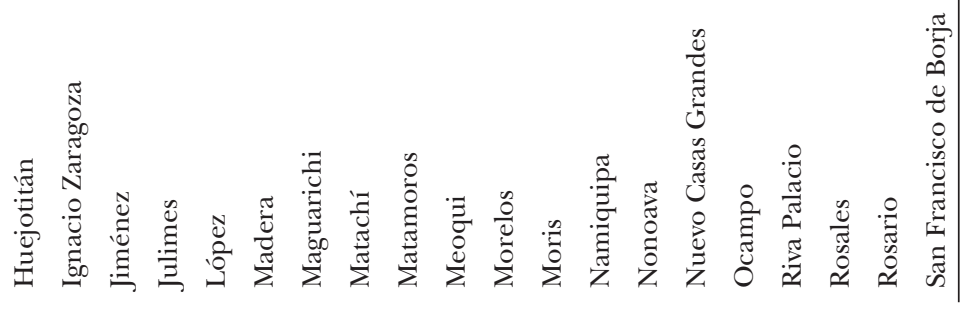




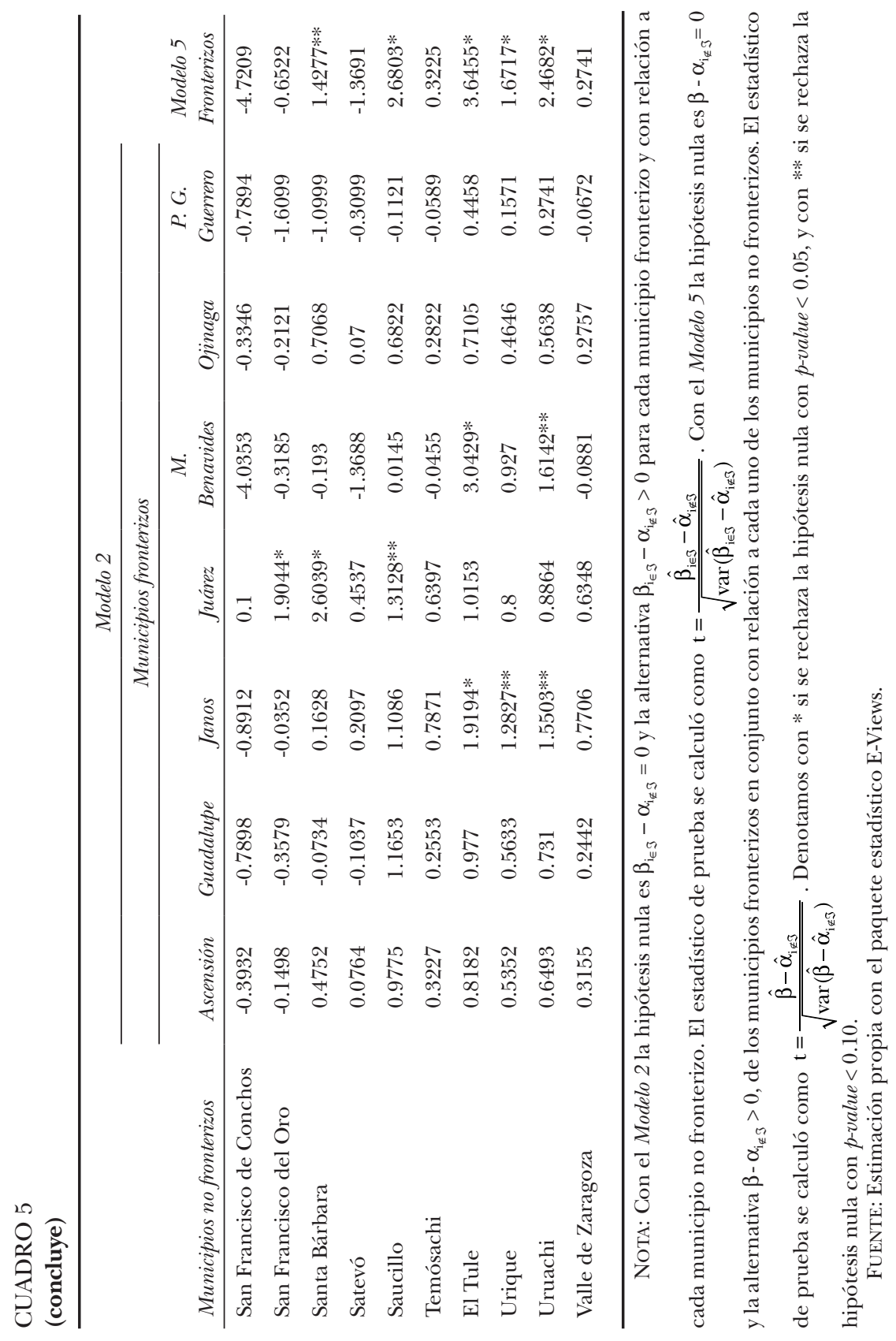


Con la reforma constitucional del Artículo 115 de 1999 es posible que las instituciones fiscales municipales sean diferentes en un mismo estado. En tal sentido, las facultades otorgadas por dicha reforma han incentivado a los municipios a explotar su capacidad fiscal.

$\mathrm{Al}$ igual que en Ibarra y Sotres (2009), en este artículo hemos estudiado tres hipótesis: que el marco institucional fiscal a escala municipal explica las variaciones en la recaudación del impuesto predial per cápita; que las diferencias institucionales en los municipios fronterizos contribuyen a explicar las variaciones en la recaudación del predial per cápita; y que la recaudación del predial per cápita de los municipios fronterizos es mayor que la de los municipios no fronterizos.

Con datos de los municipios de Chihuahua, los resultados confirmaron las dos primeras hipótesis. La tercera no fue probada en general. Sin embargo, encontramos evidencia de que la recaudación del predial per cápita de los municipios fronterizos en conjunto es mayor que la de los no fronterizos, y que la recaudación por predial de los municipios fronterizos de Janos y Juárez es mayor que la recaudación de los no fronterizos de Chihuahua. Con respecto a la versión más específica encontramos que no es posible afirmar que la recaudación del impuesto predial per cápita de cada municipio fronterizo sea mayor que la de cada municipio no fronterizo del estado de Chihuahua. Este resultado se debe a que, como se comentó en la segunda sección del artículo, y con base en los datos del cuadro 1, la dinámica económica y demográfica de los municipios en la zona fronteriza del estado no ha sido uniforme. El municipio de Juárez ha marcado el crecimiento demográfico y económico en la zona fronteriza de Chihuahua, y en buena medida ha marcado incluso la tendencia observada en el estado.

En particular, los resultados muestran que la recaudación del predial per cápita de Juárez y Janos es mayor que la de un buen número de municipios no fronterizos. De acuerdo con la especificación de los modelos estimados, este resultado es explicado por las diferencias en los marcos institucionales fiscales. Es interesante notar los contrastes entre dichos municipios. La población de Janos es de un poco más de ocho mil habitantes, participando con sólo el $0.3 \%$ de la población del estado, mientras que la de Juárez supera el millón de personas y contribuye con el $40 \%$ de la población del estado. Igualmente, la producción manufacturera y la presencia de la industria maquiladora no tienen comparación entre Janos y Juárez. Mientras que el municipio de Juárez aporta la mitad de la producción manufacturera y más de dos terceras partes del valor agregado de la maquiladora de exportación 
en Chihuahua, Janos prácticamente no registra actividad manufacturera. Tales diferencias muestran que, independientemente del grado de urbanización, el avance en el marco institucional fiscal puede mejorar la recaudación del impuesto predial.

\section{Bibliografía}

Allers, Maarten, Jakob De Haan y Sterks Cees (2001), "Partisan Influence on the Local Tax Burden in the Netherlands", Public Choice, vol. 106, pp. 351-363.

Alt, James y Robert Lowry (1994), "Divided Government, Fiscal Institutions, and Budget Deficits: Evidence from the States", The American Political Science Review, vol. 88, núm. 4, pp. 811-828.

Arroyo, Francisco (2001), "Dinámica del PIB de las entidades federativas de México, 1980-1999”, Comercio Exterior, vol. 51, núm. 7, pp. 583-599.

Bartle, John (1996), "The Effect of Intergovernmental Aid on City Property Taxes: New Results from Minnesota", Public Budgeting and Financial Management, vol. 8, núm. 2, pp. 150-169.

Bartle, John (1995), "The Fiscal Impact of Federal and State Aid to Large U.S. Cities: An Empirical Analysis of Budgetary Response", Public Budgeting and Finance, vol. 15, núm. 4, pp. 56-67.

Bell, Michael y John Bowman (1987), "The Effect of Various Intergovernmental Aid Types on Local Own-Source Revenues: The Case of Property Taxes in Minnesota Cities", Public Finance Quarterly, vol. 15, núm. 3, pp. 282-297.

Blais, André y Richard Nadeau (1992), "The Electoral Budget Cycle", Public Choice, vol. 74, núm. 4, pp. 389-403.

Buchanan, Shepard y Bruce Weber (1982), "Growth and Residential Property Taxes: A Model for Estimating Direct and Indirect Population Impacts", Land Economics, vol. 58, núm. 3, pp. 324-337.

Cabrero Mendoza, Enrique (1999), "Tendencias financieras y estrategias innovadoras en las haciendas municipales. Una aproximación metodológica para su estudio", en E. Cabrero Mendoza (coord.), Los dilemas de la modernización municipal. Estudios sobre la gestión hacendaria en municipios urbanos de México, México, Centro de Investigación y Docencia Económicas / Miguel Ángel Porrúa.

Chiquiar, Daniel (2005), "Why Mexico's Regional Income Convergence Broke Down", Journal of Development Economics, vol. 77, núm. 1, pp. 257-275.

Deichmann, Uwe, Somik V. Lall, Stephen J. Redding y Anthony J. Venables (2008), "Industrial Location in Developing Countries", The World Bank Research Observer, vol. 23. núm. 2, pp. 219-246.

Farnham, Paul G. (1990), "The Impact of Citizen Influence on Local Government Expenditure”, Public Choice, vol. 64, núm. 3, pp. 201-212. 
Feld, Lars y Gebhard Kirchgässner (2001a), "Does Direct Democracy Reduce Public Debt? Evidence from Swiss Municipalities”, Public Choice, vol. 109, pp. 347-370.

Feld, Lars y Gebhard Kirchgässner (2001b), "The Political Economy of Direct Legislation: Direct Democracy and Local Decision-Making”, Economic Policy, vol. 16, núm. 33, pp. 329-367.

Fuentes Flores, César (2001), "El manejo del suelo urbano en las ciudades fronterizas mexicanas”, Comercio Exterior, vol. 51, núm. 3, pp. 189-195.

Galli, Emma y Stefania Rossi (2002), "Political Budget Cycles: The Case of the Western German Länder”, Public Choice, vol. 110, núm. 3, pp. 283-303.

Greene, William (2008), Econometric Analysis, Upper Saddle River, Pearson Prentice Hall.

Guerrero Amparán, Juan Pablo y Tonatiuh Guillén López (coords.) (2000), Reflexiones en torno a la reforma municipal del Artículo 115 constitucional, México, Centro de Investigación y Docencia Económicas / Miguel Ángel Porrúa.

Guillén López, Tonatiuh (1990), "Servicios públicos y marginalidad social en la frontera norte”, Frontera Norte, vol. 2, núm. 4, pp. 95-119.

Guillén López, Tonatiuh (1996), Gobiernos municipales en México: entre la modernización y la tradición política, México, El Colegio de la Frontera Norte / Miguel Ángel Porrúa.

Guillén López, Tonatiuh y Alicia Ziccardi (coords.) (2004), Innovación y continuidad del municipio mexicano. Análisis de la reforma municipal de 13 estados de la República, México, Instituto de Investigaciones Sociales, UnAM / Miguel Ángel Porrúa.

Hagen, Terje y Signy Vabo (2005), "Political Characteristics, Institutional Procedures and Fiscal Performance: Panel Data Analyses of Norwegian Local Governments, 1991-1998”, European Journal of Political Research, vol. 44, núm. 1, pp. 43-64.

Hanson, Gordon (2007), "Globalization, Labor Income, and Poverty in Mexico", en A. Harrison (coord.), Globalization and Poverty, Chicago, University of Chicago Press / National Bureau of Economic Research, pp. 417-456.

Heinze, Edward (1978), "Community Classification and Growth in Effective Property Tax Rates: A Case Study of Rate Divergence in 39 Rhode Island Towns", American Journal of Economics and Sociology, vol. 37, núm. 3, pp. 309-324.

Henry, Mark y Kathy Lambert (1980), "The Impact of New Industry on County Government Property Tax Revenue”, Southern Journal of Agricultural Economics, vol. 12, núm. 1, pp. 193-197.

Ibarra Salazar, Jorge y Lida Sotres Cervantes (2009), "Determinantes de la recaudación de impuesto predial en Tamaulipas: Instituciones y zona frontera norte”, Frontera Norte, vol. 21, núm. 42, pp. 165-192.

Inman, Robert (1979), "Subsidies, Regulations, and the Taxation of Property in Large U.S. Cities”, National Tax Journal, vol. 32, núm. 2, pp. 159-168. 
Kelsey, Timothy (1993), "Fiscal Impacts of Population Growth and Decline in Small Communities", American Journal of Agricultural Economics, vol. 75, pp. 1169-1172.

Kiewiet, Roderick y Kristin Szakaly (1996), "Constitutional Limitations on Borrowing: An Analysis of State Bonded Indebtedness", Journal of Law, Economics and Organization, vol. 12, núm. 1, pp. 62-97.

Margáin, Eduardo (1999), "Globalización y desarrollo sustentable en la frontera de México y Estados Unidos”, Comercio Exterior, vol. 49, núm. 10, pp. 871-877.

Mendoza, Eduardo (2001), "Specialization, Agglomeration and Urban Manufacturing Growth in the Northern Border Cities of Mexico", Journal of Borderlands Studies, vol. 16, núm. 2, pp. 71-98.

Mendoza, Eduardo (2005), "El TLCAN y la integración económica de la frontera México-Estados Unidos: Situación presente y estrategias para el futuro”, Foro Internacional, vol. 45, núm. 3, pp. 517-544.

Merrifield, John (2000), "State Government Expenditure Determinants and Tax Revenue Determinants Revisited”, Public Choice, vol. 102, pp. 25-50.

Mungaray, Alejandro y Cuauhtémoc Calderón (2001), "La economía fronteriza como umbral de una América del Norte de las regiones", Comercio Exterior, vol. 51, núm. 3, pp. 179-180.

Petterson-Lidbom, Per (2001), "An Empirical Investigation of the Strategic Use of Debt”, Journal of Political Economy, vol. 109, núm. 3, pp. 570-583.

Rosenberg, Jacob (1992), "Rationality and the Political Business Cycle: The Case of Local Government”, Public Choice, vol. 73, núm. 1, pp. 71-81.

Santana Loza, Salvador (2000), "Acciones necesarias para la implementación de la reciente reforma al Artículo 115 constitucional: Aspectos hacendarios", Hacienda Municipal, Guadalajara, vol. 72, pp. 15-22.

Santana Loza, Salvador y Cecilia Sedas Ortega (1999), "El Artículo 115 constitucional y sus reformas: Comentarios a los aspectos hacendarios de la reforma de 1999", Hacienda Municipal, Guadalajara, vol. 68, pp. 21-35.

Shadbegian, Ronald (1999), "The Effect of Tax and Expenditure Limitations on the Revenue Structure of Local Government, 1962-1987”, National Tax Journal, vol. 52, núm. 2, pp. 221-238.

Stine, W. (1985), "Estimating the Responsiveness of Local Revenue to Intergovernmental Aid”, National Tax Journal, vol. 38, núm 2, pp. 227-234.

Stine, William (1994), "Is Local Government Revenue Response to Federal Aid Symmetrical? Evidence from Pennsylvania County Governments in an Era of Retrenchment", National Tax Journal, vol. 47, núm. 4, pp. 799-816.

Vogel, Robert y Robert Trost (1979), "The Response of State Government Receipts to Economic Fluctuations and the Allocation of Counter-Cyclical Revenue Sharing Grants", The Review of Economics and Statistics, vol. 61, núm. 3, Harvard, pp. 389-400.

Weber, Bruce y Shepard Buchanan (1980), "The Impact of Population Growth 
on Residential Property Taxes", Western Journal of Agricultural Economics, vol. 5, núm. 2, pp. 177-184.

Wilford, Walton (1965), "State Tax Stability Criteria and the Revenue-Income Elasticity Coefficient Reconsidered”, National Tax Journal, vol. 18, núm. 3, pp. 304-312.

\section{Material procedente de internet:}

CIDAC (2001), "Elecciones municipales de Chihuahua 2001", Chihuahua, Centro de Investigación para el Desarrollo, A.C. <http://www.cidac.org/ vnm/xls/chihuahua_01.xls> (octubre de 2008).

CIDAC (2004), "Elecciones municipales de Chihuahua 2004", Chihuahua, Centro de Investigación para el Desarrollo, A.C. <http:/ /www.cidac.org/ vnm/xls/chihuahua_04.xls> (octubre de 2008).

Código Fiscal del Estado de Chihuahua, Chihuahua <http:/ /www.ordenjuridico. gob.mx/EnFe/ CHIHUAHUA/legislativo.php> (abril de 2009).

Código Municipal para el Estado de Chihuahua, Chihuahua <http://www. ordenjuridico.gob.mx/EnFe/ CHIHUAHUA/legislativo.php $>$ (abril de 2009).

IMIP, Municipio de Juárez, Chihuahua, Instituto Municipal de Investigación y Planeación <http:/ / www.imip.org.mx> (mayo de 2009).

INEGI (1995), I Conteo de Población y Vivienda 1995, México, Instituto Nacional de Estadística, Geografía e Informática <http://www.inegi.org.mx/inegi/ default.aspx?s=est\&c=11881> (noviembre de 2008).

INEGI (1999), Censos económicos 1999, México, Instituto Nacional de Estadística, Geografía e Informática <http://www.inegi.org.mx/est/contenidos/ espanol/proyectos/censos/ce1999/saic/default.asp? modelo=CMAP $\& \mathrm{~s}=\mathrm{est} \& \mathrm{c}=10354>($ noviembre de 2008) .

INEGI (2000), XII Censo General de Población y Vivienda 2000, México, Instituto Nacional de Estadística, Geografía e Informática <http:/ /www.inegi.org. $\mathrm{mx} /$ inegi/default.aspx?s=est\&c $=10252>$ (noviembre de 2008).

INEGI (2004), Censos económicos 2004, México, Instituto Nacional de Estadística, Geografía e Informática <http://www.inegi.org.mx/est/contenidos/ espanol/ proyectos/censos /ce2004/cuadrosce04_.asp?c=10371\&s=est $>$ (noviembre de 2008).

INEGI (2005), II Conteo de Población y Vivienda 2005, México, Instituto Nacional de Estadística, Geografía e Informática <http:/ / www.inegi.org.mx/ inegi/ default.aspx?s=est\&c=10394> (noviembre de 2008).

INEGI (2007a), Industria maquiladora de exportación. Febrero 2007, México, Instituto Nacional de Estadística, Geografía e Informática <http:/ /www.inegi. gob.mx/prod_serv/contenidos/espanol/catalogo/> (noviembre de 2008). 
INEGI (2007b), "Finanzas públicas municipales", consulta interactiva de datos, México, Instituto Nacional de Estadística, Geografía e Informática <http:/ / www.inegi.org.mx/est/contenidos/espanol/proyectos/continuas/economicas/bd/FinanzasPublicas/FPMun.asp?s=est\&c=11289> (octubre de 2008).

INEGI (2007c), Producto interno bruto por entidad federativa, México, Instituto Nacional de Estadística, Geografía e Informática, Banco de Información Económica <http://dgcnesyp.inegi.org.mx/cgi-win/bdieintsi.exe> (julio de 2008).

Ley de Catastro del Estado de Chihuahua, Chihuahua <http:/ / www.ordenjuridico. gob.mx/EnFe/ CHIHUAHUA/legislativo.php> (abril de 2009).

SHCP (2007), "Diagnóstico integral de la situación actual de las haciendas públicas estatales y municipales 2007”, México, Secretaría de Hacienda y Crédito Público, Unidad de Coordinación con Entidades Federativas <http:// www.apartados.hacienda.gob.mx/ ucef/index.html> (abril de 2008).

\section{Acerca de los autores}

Jorge Ibarra Salazar es doctor en Economía por la Universidad Metodista del Sur (Estados Unidos), institución donde también obtuvo una maestría en Economía; además cuenta con una maestría en Economía Industrial por la Universidad Autónoma de Nuevo León. Se tituló con mención honorífica en la licenciatura en Economía del ITESM.

Entre sus líneas generales de investigación actuales figuran: federalismo fiscal en México, desempeño de los gobiernos estatales, medición de eficiencia, microeconomía aplicada y economía de la incertidumbre. Sus investigaciones han sido publicadas en memorias de congresos académicos, documentos de trabajo y revistas especializadas sobre economía.

Actualmente es profesor asociado del Departamento de Economía del ITESM, campus Monterrey, y profesor visitante en el Departamento de Economía de la Southern Methodist University. Es Investigador Nacional nivel I del Sistema Nacional de Investigadores (SNI).

Lida Sotres Cervantes estudió la maestría en Negocios Internacionales, impartida conjuntamente por el Tecnológico de Monterrey y Thunderbird, The American Graduate School of International Management; se tituló de la licenciatura en Economía del Tecnológico de Monterrey.

Entre sus líneas de investigación se encuentran: finanzas públicas subnacionales, modelos de pronósticos, estimación de modelos de 
demanda, análisis económico regional y evaluación del desempeño gubernamental de estados y municipios. Sus investigaciones han sido publicadas en los documentos de trabajo del Departamento de Economía del ITESM, en memorias de congresos académicos y en revistas nacionales de economía.

Actualmente es investigadora asociada de la Cátedra de Investigación Desarrollo Económico y Social del Departamento de Economía del Tecnológico de Monterrey. 
